\title{
Rescatando la memoria del abuelo
}

Recovering the memory of grandfather

Luz Maritza Hoyos Alegría mari6141@ hotmail.com

Universidad de Chile

Chile

\section{RESUMEN}

Este escrito sobre mi genealogía surge como consecuencia del desarrollo de una clase de literatura judía. La escritora se sumerge en recuerdos de una frase pronunciada por su abuelo siendo ella niña "Malditos judíos, judíos marranos".

PALABRAS ClAVE: Memoria, Genealogía, Recuerdos familiares, Transmisión de valores, judíos.

\begin{abstract}
This written about genealogy arises from the development of a class of Jewish literature. The writer is immersed in memories of a sentence uttered by her grandfather when she was a child “Damn Jews, Marranos Jews”.

KEYWORDS: Memories, genealogy, family transmission of values, Jews.
\end{abstract}

"Siendo niña y estando un día mi abuelito Moisés con unas copas de más, dijo unas palabras que nunca pude borrar de mi mente y las atesoré en mi corazón: ¡¡iMalditos judios, judíos marranos!!!!” 
Llegamos hace 15 años, mi esposo y nuestras dos hijas, a Chile, migramos por un sueño de realización personal de él y mío: hacer nuestros respectivos posgrados, un sueño guardado y postergado por muchos años. ¿Por qué?... y es, ¿qué es el hombre sin un sueño?

Era como si quisiera ir hacia lo desconocido, era como querer descubrir una vida que no podía observar, era como ir a la profundidad de algo desconocido pero a su vez conocido... ¿o será que tengo alma de migrante y subyace en mi espíritu, recuerdos de migraciones pasadas?

Desde el momento en que dejé Colombia sentí que yo era como una rama desprendida de su tronco, y al desprenderme de éste obviamente moría. Al estar ya en Chile y sentir la soledad propia del inmigrante, pensé que esta soledad también podía tener sus ventajas, me hizo pensar que lo mejor para no sentirme sola era hacer algo al respecto, y debía partir por insertarme en la sociedad, por eso me dije: "bueno, siempre tuve un sueño...". Este era el de haber estudiado historia, así ingresé a la universidad, realicé un magister en humanidades, mención historia, en una de las cátedras se tocó el tema de las religiones, y dentro de ellas, el judaísmo. Casi inmediatamente sentí que eso era lo mío, que estudiar sobre el judaísmo iba a ser mi tema preferido.

Y volvió a sonar en mi cabeza la frase de mi abuelo "malditos judíos, judíos marranos”.

Nació en mí esa necesidad impetuosa e imperiosa, que dicho sea de paso me caracteriza mucho, de conocer todo lo que más pudiera sobre el judaísmo, sobre su forma de vida, sus costumbres, su pensamiento, la historia de su pueblo que yo, y la mayoría de todos nosotros, había conocido a través de la Biblia, etc. Quería saber acerca de la historia que rodeó al pueblo de Israel en el Antiguo Testamento que tiene como localización el Medio Oriente, qué pueblos tuvieron contacto con ellos, qué influencia ejercieron éstos con ellos, cómo vivieron, qué fiestas celebraban y si alguna de sus tradiciones perduraban hasta el día de hoy, entre otras cosas; todo lo que tuviera que ver con ellos me interesaba, por ende, comencé a investigar.

¿Por qué me gusta tanto el judaísmo?, e intento responder: ¿será porque en el judaísmo se apela tanto a la memoria? Invita a buscar entre nuestros antepasados, conocer las costumbres que los identificaron, ¿o será porque quedaron grabadas en mi mente las palabras de mi abuelo Moisés? 
Por otro lado me llamaba la atención la relación especial de Dios con este pueblo en específico, tal como lo había leído en la Biblia. Y, a su vez me intrigaba investigar cómo un pueblo tan antiguo, con una historia que supera los 5.000 años, logró sobrevivir y sobreponerse a tantas adversidades, y por qué se les recuerda a ellos más que a otros que fueron sus contemporáneos. Pienso que este pueblo debe tener algo especial y seguramente todas estas inquietudes que he manifestado son las que me motivaron a conocerlo en profundidad y en cada área de su desarrollo.

Y así ingresé a la Universidad de Chile a su Centro Estudios Judaicos. En una clase se habló sobre la genealogía, el tema me interesó mucho, porque hablar de genealogía nos lleva a recordar a nuestra familia, a hablar de nuestros recuerdos, de los fantasmas del pasado, de familias que escribieron la historia que vivimos hoy, es recordar nuestro origen y nos insta a no olvidar a aquellos que nos antecedieron, porque cuando nos olvidamos de ellos, una parte de nosotros también muere con ellos. Hablar de nuestra genealogía es mantener viva la memoria de aquellos que nos amaron, nos aman y nos seguirán amando.

Pienso justamente en mi abuela por ejemplo, una mujer que se perdió en la memoria del olvido, padecía de Alzheimer, pero en un momento maravilloso de resplandor no sé cómo ni en qué instante y faltándome un día para salir de mi patria, Colombia, para llegar a estas tierras chilenas, mi abuela tuvo un destello de luz y un destello de memoria: no sé cómo, ni por qué ella supo que su nieta viajaba para Chile. Fue así como, sorpresivamente, ella se levantó de su cama y le dijo a mis tías: "Quiero ir a despedirme de mi nieta porque no la voy a volver a ver". Ese día, el 28 de junio de 1998, vi a mi abuelita Blanca Sandoval de Alegría, lúcida por última vez, se despidió de mí con la ternura y el amor que siempre la caracterizaron, para luego regresar a su casa, a la cama que siempre la acunó, y nunca más volvió a recuperar la memoria. Mi abuela moriría dos años después de haberme alejado de Colombia.

Ella la primera que fue afectada por el reloj de la vida, porque luego fueron muriendo los miembros más adultos de mi familia: dos tías abuelas de 102 y 104 años y muchos tíos más, de los que luego hablaré. A otros miembros los volví a ver de vez en cuando y con otros nos 
comunicamos, más aún con todo el avance de la tecnología en nuestra era, donde las distancias se acortan y sentimos cercanos a aquellos que están distantes.

Siempre pensé que las personas que no saben de dónde vienen o no saben su origen real, tampoco saben para dónde van, porque el pasado nos da las raíces sobre las cuales construimos lo que somos, el pasado son nuestros antepasados, ellos nos marcan, aprendemos de ellos, para bien o para mal; somos su reflejo y, de hecho, hasta nuestros propios hijos tienen rastros de ellos. Si tenemos el privilegio, como lo he tenido yo, de saber algo de nuestros tatarabuelos, puedo pensar y deducir que tengo muchas actitudes frente a la vida que ellos tuvieron y eso me hace mirar hacia el futuro con orgullo, con alegría, optimismo, y por qué no decirlo, con sabiduría porque he aprendido de los errores que ellos cometieron.

Hace poco hice un viaje a Colombia para asistir a la boda de uno de mis hermanos menores. Un día antes de la boda, con mi esposo viajamos a Palmira a visitar a mi suegra; el trayecto de Cali a Palmira lo realizamos en bus, una forma de viaje que me es muy cómoda, porque así puedo admirar el paisaje, los cultivos de caña de azúcar con ese olor dulce que es inolvidable. Ese trayecto tiene un verde maravilloso, del cual siempre he estado enamorada. Lo adornan unos árboles de un verdor muy particular, son conocidos como samanes y dan una sombra espectacular; son tan grandes que pueden darle sombra a una casa de campo grande o a una casa patronal sin ningún problema; cada vez que paso y los veo, me hacen pensar: ¡cuántas personas se habrán abrigado a la sombra de estos árboles! ¡cuántos paseos de campo y en familia se habrán celebrado debajo de la sombra estos árboles! ¡cuántas personas habrán tenido a la sombra de ellos encuentros furtivos de amor! Jorge Isaac relata en su novela, la historia de una pareja que, bajo la sombra de un samán, se juraron amor eterno...¡Ay, mi Valle del Cauca, cuánto te amo, tierra mía, tus verdes paisajes me enamoran y me hacen vibrar y suspirar!

Volviendo al motivo principal de mi último viaje a Colombia: el matrimonio de mi hermano Alonso. Recuerdo que llegamos con mi esposo al aeropuerto de Palmaseca, allí esperamos a que mi hermano fuese a buscarnos. Al verlo, no sabía bien qué hacer, aunque creo que mi cara de aterrada lo dijo todo: ¡Era mi hermano con su flamante novia! ¡Una joven muchísimo menor que él! ¡Tenía 25 años menos que él! Muy linda, pero parecía más su hija que su novia. Aunque, si él 
estaba feliz, yo me alegraba por él también. En el trayecto del aeropuerto a la casa de mi mamá, empezó a contarnos acerca de todos y cada uno de los preparativos de su boda, entre éstos estaba el curso prematrimonial que debieron tomar con un sacerdote, era la única forma para que se pudiesen casar por la Iglesia Católica, porque mi hermano estuvo casado hace 20 años y nunca quiso rehacer su vida. Pienso que debe haber sido porque siempre en su corazón guardó la esperanza de que su esposa volviera con él, aún sabiendo que ella ya se había casado y tenía hijas con su segundo marido. Mi hermano la seguía esperando, pero no fue sino hasta el año pasado, cuando ella viajó de visita desde España a Colombia con su esposo y sus dos hijas, que él al fin comprendió cuál era su realidad, allí tomó la decisión de volverse a casar. Me contó del famoso cursillo que tuvieron que tomar, nos comentó del sacerdote, quien resultó ser todo un personaje, les hizo escribir alrededor de diez hojas a cada uno en la que debían demostrar las razones por las que querían enlazar sus vidas. Pues bien, lo hicieron y el día que debían leer sus escritos, en voz alta, el cura se quedó dormido.

El curita había dado orden expresa de que la ceremonia debía comenzar a las 18:30, tenía órdenes expresas de que si se atrasaba la novia, ésta debía ingresar a la iglesia sin marcha nupcial. Pues bien, todos llegamos rápido y temprano a la iglesia. Mi hermano solicitó que la ceremonia fuera privada. Para todos fue una tremenda sorpresa que cuando entramos a la iglesia, ésta estaba llena de feligreses del barrio. Fue bastante pintoresco ver a una cuadrilla de ancianitas que adornaban las primeras bancas, todas rezaban el rosario ¡a todo pulmón! Tanto fue que mi hermano tuvo que acercarse y decirles que era una ceremonia privada y que la novia ya iba entrar, que por favor se mantuvieran en silencio. Finalmente, ingresó la novia, se tocó la música, ingresaron, los acólitos o monaguillos que quemaban incienso. Tras ellos, se suponía que venía el curita pero, de pronto, se pararon las viejitas que rezaban en la primera fila, y luego, apareció un caballero con una Biblia enorme y levantada, tras esta verdadera procesión con toques carnavalescos, ingresó por fin el sacerdote. Finalmente el curita se paró frente a todas las personas que estábamos en la iglesia y nos dijo que debajo de cada silla había una hoja para que siguiéramos el estricto orden de la ceremonia allí descrito, y de repente, cual profesor nos hizo mirar una cartelera, que parecía más bien hecha por un niño, y nos hizo a todos repetir lo allí estaba escrito. Para ese instante mi 
sobrino y yo nos mirábamos atónitos y me dice, con su tono español: ¡¿qué le pasa a este tío?! Le contesté: ¡No sé, hijo, pero todo parece muy macondiano!

Llegó el momento en que los novios debían intercambiar las argollas, pero, antes de que llegaran al altar, el paje que llevaba los anillos, sin querer las dejó caer al piso. Finalmente terminó la misa y como para cerrar con broche de oro aquella ceremonia "macondiana", apareció el típico borrachito, que no falta en ningún lado, y se paró atrás de la iglesia, y no se le ocurrió nada mejor que gritar a toda voz: “¡Viva Cristo! ¡Cristo vive!” Gritaba una y otra vez, tanto así que ni siquiera se escuchó la marcha nupcial a la salida de los novios.

Pero bueno, este es mi país, mi tierra bonita, donde nos tomamos todas las cosas con humor y no le ponemos mayor gravedad al asunto. De algún lado Gabriel García Márquez debía sacar inspiración para su pueblo Macondo.

El matrimonio de mi hermano, me sirvió para hablar de algunos miembros de la familia de mi abuelo, que aún viven. Acordamos reunirnos al día siguiente del matrimonio y degustar una rica comida, propia de la familia y de la región de donde provenía mi abuelito. Y así fue que nos reunimos todos en la casa de mi mamá, Esperanza Alegría, casada con mi padre, Noel Hoyos López. A algunos de los familiares no los conocía, a otros no los veía desde hace unos treinta años, así que el reencuentro fue más que emotivo. Busqué en muchas caras y vi parecidos increíbles, era como ver a muchos tíos abuelos, en una versión actualizada o en versión mujer. Es increíble que los fenotipos no se pierden aunque se mezclen, simplemente no se pierden. A los familiares que no conocía pareciera como si los hubiera conocido de toda la vida, todos eran muy cariñosos y le hacían honor al apellido que portan: Alegría. La verdad es que fueron momentos muy bellos y especiales.

Mi madre y mi hermano menor prepararon unos ricos tamales. Los tamales son un plato muy típico colombiano, pero éstos, los que prepara mi mamá, son los más especiales del país. Se diferencian de todo el resto de Colombia, porque la papa que utilizan y el condimento con el que se preparan son especiales. El nombre de estos tamales es "tamales de pipián". En general, los tamales se caracterizan ser una especie de envoltura de hoja de plátano que va relleno con un guiso muy rico. En la región de donde proviene la familia de mi abuelo, Departamento del Cauca, 
se cultiva una papa muy particular, que al cocinarla tiene un rico sabor a mantequilla. Esta papa es la base del guiso para hacer el relleno, que lleva también carne de pollo y otras especias; algunas personas a veces en vez de pollo le colocan carne de cerdo. Los tamales tienen una preparación un poco larga, cuando ya están listos para ser servidos, se les acompaña con ají de maní y quedan realmente exquisitos.

Pero más allá de lo rico de los tamales, cabe señalar que en un comienzo, la reunión se había ejecutado en silencio. Quizás porque todos estábamos rememorando, iy cómo no hacerlo!, nuestra infancia, esos tamales nos estaban trasladando al pasado. Recordamos los sabrosos platos que nuestras madres nos preparaban, era como recordar aquello que nos hace sentir tan caucanos, lo más propio de nuestra tierra, pero más que eso, era lo que nos identificaba como familia Alegría: la memoria del olor y el sabor de la deliciosa comida familiar no se había ido nunca, el recordar sabores y olores nos hizo recordar situaciones de penas y alegrías, aunque en el caso de nuestra familia parecía que todo siempre fuera y hubiera sido alegría. Esa forma de ver la vida en mi familia de manera positiva era nuestro sello de distinción. Siempre veíamos, y vemos, la grandeza del ser, del existir y de ser familia, siempre optimistas, alegres y pensando que el día de mañana iba a ser mejor que el día que estaba terminando.

Creo que ese momento tan especial de haber probado el primer bocado de tamal a todos nos marcó, porque recordamos lo que creíamos estaba olvidado. Recordamos lo que creíamos estaba muerto, rememoramos el pasado y había llegado hasta ese presente; trajimos, en definitiva, a nuestros antepasados a la reunión y eso fue lo que permitió que fuera una cita inolvidable. Allí habían estado esperando, aguardando a ser rescatados de nuestras memorias.

Y así comenzó nuestra animada reunión, tras haber comido unos ricos tamales y una exquisita torta, pues coincidió que ese día era el de mi cumpleaños, fue un día de pura felicidad. Hablar sobre la familia, sobre los que descansan en paz y sobre sus anécdotas es como transportarse al pasado y vivir un poco de lo que ellos vivieron también. Para mí es como hablar de historia patria, pues mi bisabuelo y mi tatarabuelo participaron en dos guerras muy importantes para nuestro país, siendo ambos generales. Eso me hace sentir realmente orgullosa de mi familia. 
Hablar sobre mi genealogía me tenía emocionada hasta los tuétanos, pues como todos sólo conocía una parte, la parte que contaban mi madre y sus hermanas, pero conocer por boca de otros diferentes anécdotas y aspectos de su vida era algo fascinante, así que comencé a indagar, a rescatar lo vivo de lo olvidado, sin duda era mi oportunidad de conocerlos un poco más. Era como si me dijeran: "si tú no preguntas hoy sobre nosotros y nos dejas en las profundidades del olvido, una parte de ti nosotros nos la llevaremos” ¡Sí! Ellos me estaban aguardando, eran inmateriales, pero ahora volvían a cobrar vida en los recuerdos de la familia, porque la palabra es vida, ahora ellos estaban más vivos que nunca; fueron y eran fieles con su familia, volvían para estar en la memoria y boca de sus seres amados.

Así que aprovechando la reunión les di a todos una explicación acerca de mi proyecto, acerca de la investigación que debía realizar sobre nuestra genealogía, la de la familia Alegría.

Comencé preguntándole a Nelly, prima hermana de mi mamá, la mayor de las primas. Generé una suerte de encuesta: ¿Qué recuerdas de tu abuelo? ¿Cómo se llamaba él? Que yo recuerde su nombre era Guillermo Alegría Solano, él tenía una finca hacia el lado de Las Tres Cruces. Luz Dary, la hermana mayor de mi mamá, interrumpe y dice que él tenía un fundo que se llamaba "Pan de azúcar”. Nelly continuó hablando y dijo: “ino! no era ése, era más cerca, acuérdate, Luz, que estaba atrás del cerro de Las Tres Cruces, ese sector se llama La Golondrina, allí íbamos a pasar las vacaciones con las tías Luisa y Carmen y con las otras primas, Nelly y Miriam, nos mandaban para allá porque seguramente dábamos mucha lata en la casa. Tenían una casa de campo muy grande, muy linda, en las tardes solíamos ir a cabalgar y que yo recuerde montábamos de a dos, porque yo le tenía pavor a esos animales, cuando me subía me agarraba del que iba llevando las riendas y no lo soltaba hasta llegar de nuevo a la casa”. Bueno y, ¿se acuerdan cómo era la relación de mi bisabuelo con su esposa? "En primer lugar la abuelita se llamaba Clotilde. Ellos se llevaban bien, por lo que recuerdo, la abuelita era seria, pero cariñosa. Una mujer de armas tomar, debía de serlo porque para dirigir tremenda casa y, aparte haber quedado viuda cerca de los cincuenta años, debía de serlo. Al abuelo le encantaba echarle piropos a las muchachas". Y, ¿qué comida le gustaba a él que le prepararan de una manera especial? "Bueno a él le gustaba mucho el sancocho de costilla, también le fascinaba el mote". Milena, otra prima, interviene y dice: “ $i s i ́$, le gustaba el grano reventado! y a eso le colocaban hojas de 
repollo, frijoles, y ese era el plato especial de los Alegría”, ¡ah! entonces le gustaba, el frijol verde, con repollo, choclo y mote, digo yo. Luego les digo: ¿qué otras cosas en especial les gustaba? Todas contestaron al unísono: ¡De todo! Marlene, hermana de mi mamá, a quien cariñosamente le decimos 'Chava' dice: "pues, como eran gente de campo, comían de todo". Luz Dary señala a su vez: "ellos eran muy amplios". Nelly dice: "sí, le encantaban las tostadas de plátano". Les comento que hablando un ratito con mi prima María Victoria, hija de Marlene, ella me cuenta que a nuestro abuelo Moisés no le gustaba el pescado. “¡Cómo que no!” exclamó la tía Luz Dary, "a él le encantaba, en especial la corvina, el pargo rojo y el bagre". Vicky dice: "bueno es lo que yo me acuerdo". Vuelvo a tomar la palabra y pregunto: "Cuéntenme, ¿a él le gustaba el pescado con escamas o sin escamas?", "si a él lo que fuera pescado le fascinaba, sólo que a Marlene y a Esperanza nunca le gustó, lo que pasa - dijo Luz Dary - es que a mi mamá no le gustaba, y como a ella no le gustaba no lo preparaba, pero mi papá Moisés a mí me enseñó a prepararlo".

"Recuerdo, tía, que en algunas ocasiones el tío Marceliano, hermano de mi abuelito Moisés, venía de visita a la casa y la verdad es que yo lo veía tan grande casi como un gigante, y yo estaba tan pequeña". Mi prima Vicky, a manera de broma, dice: "Bueno, tú sigues igual", cosa que es muy cierta, sigo siendo la misma chiquitita de siempre. Nelly, hija mayor de Marceliano, contesta: "sí, pues él era el más grande de todos, el más alto, media como 1.90mts".

"Recuerdo también que iba con mi papito Moisés a visitar al tío Luisimaco. Él siempre estaba en su oficina, muy bien vestido, pero muy serio, él era muy elegante y su casa siempre estaba muy linda también. Sin embargo, era poco cariñoso, era muy distinto al resto de todos los hermanos", "sí -me dice Nelly-, era muy serio, pero no repelente. Era un hombre muy callado y se preocupó mucho de que sus hijos fueran profesionales; uno fue arquitecto, y dos más fueron médicos. Bueno y ni qué hablar de la tía Carmen...”, “ ¡Ah sí! -dijo Milena, hija de Francisco, otro hermano de mi abuelo-, la tía Carmen siempre poniéndole apodos a todos, siempre riéndose, era como la característica de la familia. ¡Ah! Y cómo no recordar a la tía Luisa, era la más alegre de todos, nunca se casó para no dejar sola a Carmen, quien por lo alta no encontraba marido. Fueron unidas hasta en la muerte. Fíjate que hace cinco años murió Carmen, tenía 104 años, y Luisa la llamaba llorando: ¡hermanita no me dejes sola! Y a los dos días murió la tía Luisa de 102 años, las dos 
estaban completamente lucidas. ¿Sabes, Maritza? Ella se parecía mucho a ti. Ella fue la que anotó los datos que están en este libro viejo que yo quiero tú tengas. Ella era muy cariñosa y alegre, siempre anotando las cosas importantes de la familia, siempre tan social....". La interrumpo y le digo: "lástima no parecerme más a ella, por lo menos en la estatura, digo yo, ojalá me hubiera regalado un poquito”. Me pregunto, ¿por qué si eran tan altos todos me tocó a mí la suerte de ser chica? "Pues por su papá, mijita", contestó mi mamá. Y todos rieron.

"Bueno, quería preguntarles a ustedes las mayores si tienen algún recuerdo de que los hermanos Alegría se juntaron para ocasiones especiales todos, ¿tienen algún recuerdo de eso?" "De haberlos visto a todos juntos -Nelly dice- que yo recuerde, no, porque siempre estaban dispersos entre Cauca y el Valle del Cauca; pero mi mamá me dice que cuando ustedes vivían en Popayán, mi papito Moisés organizaba unas fiestas grandes y hasta preparaba el vino en unos grandes toneles, porque venía toda la familia y se quedaban como una semana de fiestas". Luz Dary dijo: “claro, acuérdate que en la época en que fue juez de rentas y ejecuciones fiscales en el Cauca y aquí en el Valle, él nos dejaba hacer fiestas a nosotras cuando estábamos jóvenes y él mismo preparaba los cócteles, y las primas todas viajaban a Popayán a las fiestas. Él invitaba a toda la familia a las celebraciones". Mi hermano Alonso, que hasta ese momento había estado muy callado, preguntó: “¿y cuáles eran los apodos que ellos se ponían? Luz Dary dijo: “a la tía María Luisa le decían 'la cuica", “¿y por qué le decían la cuica?”, dije yo, “la verdad yo no sé”, dijo Luz Dary. Alonso dijo: "a mí me decían 'Tufi', mi madre Esperanza dijo que a mi papá le decían 'Torcuato", no pude evitar preguntar: “¿Mami, y por qué le decían Torcuato?”, mi madre señala: "porque era el más bajito de todos, y por la cojera que tenía”. "Bueno, ¿y a qué se debía su cojera?” “¡Ah! -dijo Luz Dary- es que cuando él fue director de la cárcel en Popayán, se le escapó un preso, y él salió con los guardias a buscarlo como a las seis de la tarde, y le dijeron que se encontraba en el sector 'Los brazos' en Popayán, un sitio de cantinas y bares y como no lo encontraron, con los guardias se pusieron a tomar traguito y mi papa Moisés, sacó su pistola para limpiarla y como tenía la pierna doblada se le disparó, y el tiro le entró por el calcañar”. Y le pregunto a mi tía: “¿por eso tenía mi abuelo un hueco en el talón de Aquiles?”, “lo que pasa, mijita, es que en esa época la medicina estaba muy atrasada, lo llevaron a la clínica en Popayán y en vez de hacerle la tracción desde la parte de arriba de la pierna, se la hicieron del calcáreo y eso 
se le infectó y le supuró horrible, y le abrió un hueco. Tiempo después de recuperado andaba mi papá con pistola en mano buscando al médico para matarlo por el daño que le había hecho", "i¿y ustedes vieron todo eso?!", dije yo, “claro -dijo mi mamá-, nosotros lo vimos en la clínica con la pierna colgada".

“Alonso y tú, qué recuerdas de nuestro abuelo Moisés?”, "Bueno -respondió Alonso- él se enojaba conmigo porque me decía que no me fumara las colilla de cigarrillo que él tiraba, y también una vez que me regañó porque le quemé un colchón de una cama y casi incendio la casaPero él no era así un viejo enojón".

"Mira, sobrina, -me dijo la tía Luz Dary-, ahora que me acuerdo, mi papá Moisés contaba que sus papás tuvieron una finca que se llamaba 'Pan de azúcar' por allá por Timbio en Cauca, porque ellos eran de por allá. Ellos vendían ganado y vivían en la abundancia”, “¿y ustedes se acuerdan de amigos de ellos?”, les pregunté yo, “No, eso no, lo que sí es que fue muy mujeriego, dejó hijos naturales por todo lados. Sí, pero los reconoció a todos”, dijo mi mamá.

“Bueno y, ¿quién fue el que estuvo en la guerra de los mil días?”, pregunté, y Milena dijo: “en esa guerra estuvo el general Francisco Antonio Alegría, quien fue el papá de mi abuelo Guillermo Alegría Solano”. "Y, ¿cuál era el apellido y nombre completo de tu abuelo?”, seguí inquiriendo, “ ¡Ah!, mira, en este cuadernito antiguo que te estoy pasando, allí aparecen los nombres completos de los abuelos y los bisabuelos para que lo mires bien. Allí aparecen ellos y los nombres de los padrinos de sus hijos también". "Bueno, familia, yo tengo recuerdos de mi abuelo Moisés como un muy buen católico. Él quería mucho a su Iglesia y trabajaba bastante por ella siempre estaba en las procesiones de semana santa", señalé yo, "sí, -dijo Luz Dary-, mi papá Moisés regaló un Cristo para una Iglesia, creo que la del barrio Junín, era enorme, él lo pagó y lo mandó a traer de España”, “¿y todavía está?”, dije yo, “sí, todavía lo tienen allí,, señaló Luz Dary, “¿y, cómo era el resto de la familia respecto de su religiosidad?, ¿cómo vivían su catolicismo?”, cuéntame tú, Milena, le dije, “¿cómo era tu papá Francisco con respecto del Iglesia Católica? ¿Cómo la vivía él?”. “Bueno”, dijo Milena, y se quedó pensando, seguramente trayendo muchos recuerdos a su mente, "él no era tan religioso, -prosiguió-, era muy amigo de un sacerdote, el Padre Arango quien fue muy amigo de la familia Alegría, pero mi papá no, él no era 
muy amigo de ir a la Iglesia. "Él perdió la vista”, dijo Luz Dary, "y, ¿cómo perdió la vista el tío?”, le pregunté. Milena sonríe y dice: “mi papa perdió los ojos”, “¡no, ¿cómo así?!”, le dice Nelly, "él perdió la vista, porque sufría de las amígdalas y a todos los Alegría nos ha encantado el aguardiente, y el traguito, por las mañanas, mi papá abría un barcito que tenía en la casa y sacaba una botella de whisky, tomaba y hacia gárgaras con él, en vez de tomarse un remedio, un desinflamatorio, u otro remedio. Entonces cuando mi hermano y yo estábamos pequeños, mi papá un día nos llevó de paseo, mi papá no manejaba, teníamos un auto, y resulta que quedó, de un momento a otro, viendo todo verde por cuatro días". Mi mamá interrumpe y dice: "sí, mi tío perteneció a la guardia presidencial y un día se cayó de un caballo, y desde allí empezó con problemas", "sí, eso es", dice Milena, "por eso él era pensionado y luego otra vez nos llevó de paseo y la misma cosa, se agachó a recoger una bolsa y se quedó sin visión. Luego se lo llevaron al Hospital Militar en Bogotá estuvo tres meses, lo cuidó Nelly, que es su sobrina, y quien vivía allá".

“Y, Nelly, ahora cuéntame, ¿cómo era tu papá, mi tío Marceliano?”, le dije, “él fue lo más lindo que yo he conocido. Mi madre murió cuando yo tenía 8 años, y mi hermana, recién nacida. Él nos crió a mi hermana y a mí, solito. En toda nuestra niñez e infancia jamás nos abandonó. Fue el hombre más cariñoso que he conocido. Le tuve toda la confianza que una mujer le puede tener a un papá. Todos mis secretos los sabía mi papá, y para esa época era algo insólito. Vivíamos en una casa con dos habitaciones: en una dormía mi papá y en la otra mi hermana Irene y yo. Los fines de semana él trabajaba mucho, era el jefe de talleres de Cicolac. Cuando salía del trabajo quería darse sus vuelticas y tomarse una cerveza, entonces nos dejaba a mi hermana y a mí encerradas en el cuarto y mirábamos por la ventana. Resulta que estudiábamos en un colegio católico y era obligatorio ir los domingos a misa. Como era un pueblo chico todos nos conocían y mi papá se iba el sábado y regresaba el domingo como a las diez de la mañana. El problema que teníamos nosotras en el colegio el lunes, porque mi papá nos dejaba encerradas... se llevaba la llave, y, obviamente, no podíamos ir a la misa que era a las 7 de la mañana, entonces, los hijos de una vecina iban a buscar siempre a mi papá para que regresara rápido o les prestara la llave. Pero mi papá, se podía caer el mundo, y nunca soltaba las llaves. Cuando volvía ya habíamos perdido la misa y al lunes siguiente éramos castigadas y nos dejaban sin recreo. Un día estábamos muy 
chicas, mi hermana tendría como 8 años, nos sentó a las dos y nos dijo que se iba a casar. Para nosotras fue un golpe brutal. Nos dijo que necesitábamos que alguien nos cuidara, que no podíamos seguir así solitas, y que le preocupaba nuestra situación. Pasó el tiempo, se casó y llevó la señora a la casa, y las cosas cambiaron".

Puedo observar que estos hermanos Alegría tienen un común denominador: son muy amplios. Por otro lado, todos eran muy cariñosos, muy preocupados por sus hijos y, otra cosa, que me ha gustado mucho, es que todos se preocuparon porque sus hijos, sin distingo de sexo, estudiaran y fueran a la universidad. Cabe destacar que, en esa época enviar a la universidad a una hija era toda una proeza y más a la capital. Ellos también se preocuparon por ser hombres cultos y bien preparados. Seguramente, pienso yo, para que hubieran sido así es porque en su casa debieron de haber tenido un buen modelo también, y porque de alguna manera los apoyaron e impulsaron a prepararse. “¿Ustedes saben si alguna vez ellos contaron cómo fueron sus papás con ellos o no hablaban de eso?", habla mi tía Luz Dary y dice: "de la abuela recuerdo que era una mujer de armas tomar. Era un poco enojona. El abuelo era muy correcto, también de armas tomar, bueno, de algo me acuerdo. Hasta donde yo sé, mi abuelo Guillermo Alegría era de ascendencia española, eso se lo escuché decir a mi papá varias veces". "Tía Luz Dary”, le dije, "ahora que me acuerdo ¿a quién contactó mi abuelito Moisés en España para mandar a hacer el Cristo de la iglesia?", "bueno, la congregación tenía que dar donativos para que su iglesia pudiera tener el Cristo del altar mayor y mi papá lo pagó él solo, los sacerdotes hicieron el contacto". Alonso, mi hermano dice: "sería bueno ir a la iglesia y ver la inscripción por atrás del Cristo, así podríamos saber algo más, porque, que yo recuerde, los judíos paisas en sus adornos y en sus cosas de plata, también en sus ollas, colocaban, y aún hasta el día de hoy colocan, sus verdaderos apellidos judíos". "Sí", le dije, "eso es una tarea pendiente".

"Tía, -comencé con otra interrogante-, desde que yo era niña y tengo uso de razón, mi mamá Esperanza siempre ha hablado que a ti te perseguía un duende. Y ese duende llegaba donde vivían cuando el abuelito tenía la mina de oro. Recuerdo que el abuelo le ponía tacos de dinamita al árbol donde el duende se sentaba, ¿cómo fue eso?”. Mi tía, ante la carcajada general de toda la familia, se puso seria, al parecer eso era un secreto o una historia que no quería que fuera revelada. Obviamente nadie quiere ser el blanco de historias fantasmales. "Bueno -dijo mi tía-, es 
que cuando mis papás se casaron se fueron a vivir a un sitio que se llama La Vega en el Departamento del Cauca, de allí pasaron a Almager. Allí mi papá conoció a un alemán que había llegado a estas tierras escapando de la Segunda Guerra Mundial. Entre los dos compraron una mina de oro para explotarla, vivían de eso, en esos riscos por donde nace el rio Cauca, en el páramo de las papas, lo que es conocido como el macizo colombiano, donde entra la cordillera de los Andes a Colombia. Es justo ahí donde parece que empezó a molestar ese bicho o duende”, “y tú lo viste, tía alguna vez?", inquirí, "vamos despacio”, dijo ella, "sí, yo lo vi”. "Tía, ¡cuéntanos esa historia!". "Mira, sobrina, yo hablé de esto una vez con un pastor y me dijo que eso no existía, que eso era un espíritu. Yo no sé, pero la verdad, yo lo vi...pero, bueno a mi papá no le gustaba hablar de esto, era como un tema prohibido, pero mi mamá Blanca sí me contó. Al parecer el duende se enamoró de mis ojos, porque eran muy bonitos. Y, cuando yo estaba niña, venía y me echaba flores en el cabello, recogía las flores del campo y me las dejaba en la cuna o donde yo estuviera; entonces mi papá le quemaba tacos de dinamita, de las que el usaba para explotar la mina, y se los ponía en el árbol donde se posaba .Entonces los campesinos y los indígenas de por allá le dijeron a mi papá que ese era el duende, que le quemara dinamita, además de otros trucos que mi papá siguió al pie de la letra. Mi papá le tocaba una guitarra destemplada, en el sitio donde se paraba; hacía todo lo que la gente le aconsejaba que hiciera. Y así pasó el tiempo y cuando yo tenía 6 años tenía que entrar al colegio. Mis papás decidieron que era hora de llevarme a Popayán para estudiar. Recuerdo que mis papás me subieron a un caballo y me amarraron porque yo estaba pequeña, y volteo a mirar hacia un lado y veo al lado del caballo a un ser como de 50 centímetros de estatura, con un sombrero enorme, y con los pies hacia atrás, estaba al lado mío, no sé si era animal o cosa, no le vi la cara, sólo recuerdo que era un bulto con un sombrero inmenso y verde. Esperanza, mi madre, interviene y dice que su papá cuando le puso la guitarra destemplada ese duende salió a correr, y que eso es todo lo que ella sabe.”

Se produjo un silencio...todos quedamos como asustados y sin poder creer la historia que nos estaba siendo narrada por su protagonista. Era algo de lo que siempre escuché hablar a mi mamá Esperanza, pero ahora por fin lo contaba la directamente afectada. En ese mismo instante Marlene, la hermana menor e hija menor de mi abuelito Moisés, se involucró en la conversación y dijo: "bueno yo tengo algo que contar de mi padre. Él fue un hombre muy alegre, le gustaba 
mucho la música, tocaba el tiple, la bandola y el clarinete”. Recuerdo que en Popayán existían unos músicos a los que llamaban coloquialmente "chirimías", entonces, dijo Marlene: "como mi papá tocaba tanto instrumento musical, él contrataba esas bandas y se las llevaba para la casa y era feliz tocando con ellos y dirigiéndolos. Mi papá no sabía bailar, pero le encantaba que uno saliera a bailar con él. Lo que hacía era que daba vueltas alrededor de uno con un pañuelo blanco mientras nosotras bailábamos. Era feliz con el simple hecho de vernos bailar, y esa era su manera de acompañarnos. Otro recuerdo importante de mi papá, es que él fue un orador tremendo. Empíricamente fue abogado, se sabía los códigos y las leyes al derecho y al revés. Tenía una memoria prodigiosa, citaba hasta el número de la página donde se encontraban los artículos, era impresionante escucharlo. Su oratoria era muy buena, yo lo escuchaba cuando se tomaba sus traguitos y empezaba a dar sus discursos y a hablar de política. En esta área se interesó particularmente. Fue miembro del partido conservador y era seguidor de Laureano Gómez, de hecho, teníamos una pintura enorme en nuestro living de Laureano cuando fue envestido con la banda presidencial (1950-1953). Mi papá fue muy conservador y muy creyente. Cuando tomaba sus traguitos se tiraba de guata al piso y decía 'Cristo santísimo, sálvame y dame la paz', Eso me impactaba mucho. Pero volviendo al tema político, puedo decir que mi papá tenía muy buenas relaciones con ex presidentes de la República, con gobernadores, de hecho, el padrino de su boda fue el gobernador del Cauca en ese entonces, el Señor Zambrano”, “irecuerdo!”, dice Luz Dary. Mi abuelo Guillermo era amigo del que también fue político y poeta, de Guillermo Valencia, (1873-1943). Él conoció a mi papá desde pequeño, porque mi papá fue empleado público desde los trece años... jimagínense!, el poeta Guillermo Valencia le aconsejó a mi abuelo: "Guillermo, pon a estudiar a tu hijo Moisés, es un niño muy inteligente", pero mi abuelo estaba más interesado en que sus hijos trabajaran en la hacienda que tenían y supieran administrarla bien. Mi tía Marlene continúa hablando y dice: "sí, pero mi papá Moisés no se conformó con eso, él se preparó, fue un abogado sin título y fue asesor de tesis de grado de Derecho de muchos estudiantes; siempre lo buscaban para que los guiara en sus tesis y puedo decir con propiedad que le hizo la tesis a muchos abogados, era tremendo para eso. Escucharlo en la noche tecleando con dos dedos su máquina de escribir Remington, escribía rapidísimo. También escribía discursos a grandes políticos, fue amigo personal del que fue presidente de la República de Guillermo León Valencia (1962-1966). 
¡Cómo se nota el orgullo de sus tres hijas por su padre! Es cosa de ver el entusiasmo con el que hablan de él. Entre las tres se interrumpían para contar todo lo que su padre, mi abuelo, hizo. ¿Qué lindo trascender de esa manera!, jeso sí es dejar un legado!

"Bueno", les digo yo, "veo que ellos los Alegría fueron hombres muy cultos y preparados", "sí, se preocupaban mucho de eso", dijo Esperanza, "a propósito ¿ellos fueron doce o catorce hermanos?", pregunté, "fueron catorce", dice Luz Dary, "porque antes de que nacieran mi tías Luisa y Carmen, nacieron otras dos niñas y fallecieron muy niñas, así que cuando la abuela quedó después en embarazo le puso a sus otras hijas los nombres de las fallecidas", "sí”, dijo mi mamá, "también hubo un Ricardo, un Gonzalo, un Modesto", tíos nuestros que tampoco los conocimos. En total fueron cinco los tíos que no conocimos, pero en cuanto a hermanos, fueron catorce en total. “¡Cómo se nota que se querían los abuelitos!, y ¡cómo se nota también que no tenían televisor!, comenté.

"Quiero aprovechar ahora que estamos aquí reunidos, de contarles por primera vez en mi vida a toda la familia una experiencia que tuve con mi abuelito Moisés cuando era niña. Él siempre jugaba conmigo, yo solía pararme en sus pies y él cantaba y bailaba conmigo. Entonaba este estribillo: 'cuando la muñeca quiere que el muñeco vaya a misa, la muñeca se pone calzones y el muñeco, la camisa' y soltaba a reírse. Ese era nuestro juego. Le gustaba sentarse también en una mecedora y me decía que le sacara las canas, y yo me paraba en las patas traseras de su mecedora a tirarle el cabello. Él se mecía, y yo con una mano agarrada de la mecedora y con la otra arrancándole las canas. Pero un día él llegó borrachito, debo decir que me impactó mucho verlo así, pero no porque estuviese con unas copas de más, sino porque lo vi llorar... nunca lo había visto así. Junto con las lágrimas, había comenzado a decir: "si, judío maldito, judío marrano". Y desde allí nunca se me borraron aquellas palabras de mi mente, y debo decir que muchas cosas se me han borrado de mi infancia, pero esta frase en particular, y la imagen de mi abuelo llorando, me han acompañado toda mi vida. Es por eso que les quiero preguntar si alguno de ustedes tuvo alguna experiencia similar con él o que le hayan escuchado algún comentario a alguno de sus papás o tíos, porque, honestamente, siempre pensé que eran ideas mías o que tenía algún amigo imaginario al que le hubiera escuchado esta frase. Pero para mí fue una sorpresa escuchar, en una clase de diplomado, el mismo epíteto 'judíos marranos', palabras que cuando 
escucho me impactan sobremanera. Pensé por una fracción de segundos: "o me leyeron la mente, o tienen el mismo amigo imaginario que yo", pero, no, era verdad lo que escuchaba, en esa clase se hablaba de esta frase que yo sólo había escuchado una vez en la vida y había sido de parte de mi abuelo, pero ahora lo escuchaba de personas muy doctas en estos temas. Fue entonces cuando me dije: “¡Ah, Maritza, tienes que investigar! No estás loca, bueno quizás un poco, pero es mejor así. Recuerdo que mi abuelita Blanca siempre decía: 'de tontos y locos todos tenemos un poco"”.

"Más que reencontrarnos y conversar, aparte de contar algunas anécdotas de nuestras vidas, también quería contarles todo esto que he atesorado por años. Por eso les quiero preguntar, si alguna vez escucharon hablar algo al respecto, o le escucharon a sus padres hablar algo sobre una llave en especial que debían tener guardada de recuerdo, o escucharon hablar algo sobre judíos en sus hogares o participaron de algún tipo de ceremonia que puedan recordar", les insistí, pero todos se quedaron en silencio como pensando, y a su vez como extrañados de que a estas alturas de la vida, alguien en la familia hubiera tenido algo que ver con judíos. Entonces, le pregunté a la prima de mi mamá, Milena, si escuchó alguna vez hablar algo al respecto y me dijo que no, que nunca escuchó nada. Nunca nadie escuchó hablar al respecto. Mi tía Luz Dary dice que desafortunadamente en esa época nadie se preocupaba por averiguar sobre sus antepasados, ni menos por escribir de su familia. Todos me dicen que están muy emocionados con el proyecto que estoy escribiendo y aproveché para preguntarle a mi prima María Victoria Tovar, que hasta ese entonces se encontraba muy callada, ella es hija de mi tía Marlene, hermana de mi mamá, y le pedí que me contara acerca de sus experiencias con nuestro abuelo. Ella vivió con nuestro abuelito, por ende, debe tener bonitos recuerdos de él también. Pues bien, ella me dijo: "bueno, mira, la verdad es que ellos poco o nada de su vida contaban, o tampoco tenían como costumbre sentarse a contarnos cosas o historias anecdóticas. Nuestro abuelito murió cuando yo tenía 7 años, así que lo que recuerdo te lo voy a decir. Hubo un hecho en especial que siempre llega a mi mente y tiene que ver conmigo; te lo voy a contar tal y como me lo contó mi tía Luz Dary cuando mi mamá quedó embarazada. Recuerdo que ella tenía pánico de contarle a mi abuelo, imagínate en los años sesenta una señorita quedar embarazada de su novio, eso era todo un escándalo. Además, mi abuelo le había rogado que no saliera con ese señor Antonio y, como el abuelito era tan religioso y tan conservador en sus ideas, ella pensaba que la iba a matar, así que entre las 
hermanas lo sentaron en el living y la mayor, Luz Dary, le habló y le dijo el estado de mi mamá. El susto que se llevaron fue tremendo porque reaccionó parándose de su asiento y se puso delante de mi mamá; ella pensó que se le iba a ir encima, naturalmente, se asustó, pero las desconcertó completamente su actitud porque se quedó mirándola callado (y es que era una circunstancia difícil, ella era su bebé, la menor, por ende, me imagino su dolor y amor a la vez). Le dijo a mi mamá: 'tranquila, hija, yo estaré orgulloso de ser el padre de ese bebé'. Para mí, mi abuelito siempre fue mi héroe y, por supuesto, mi papá. Él curaba mis heridas con cosas como aceite de auto, recuerdo que una vez lo utilizó para curarme de una quemadura que tuve en el estómago por una leche caliente que me cayó; o el aceite de tiburón que mandó a traer del puerto de Buenaventura, para curarme una tos crónica que tenía; o cuando me contó la historia de un campesino en una manifestación política le pegó un machetazo en la cabeza y él se curó con una cáscara de plátano verde que se puso en la herida, la cual no quitó hasta que se cayó sola. ¡Ah! y el infalible café que me echaba en todas las heridas y raspaduras que me hacía. Lo recuerdo mucho trabajando en cosas de carpintería, le encantaba y le quedaban preciosas. Sin duda tenía talento para la madera, pero podía tener el martillo al lado y llamaba al que fuera para que le pasara todo, y se lo tenían que poner en la mano".

"Él tenía un dicho muy común cuando uno no encontraba algo que él pedía y que estaba enfrente de uno, decía: 'ojos en la cara, ahí está'. Recuerdo que le encantaba la época de diciembre por las famosas "chirimías". Cada vez que pasaban por la casa, las hacía entrar y como les daba su traguito en cantidades, pues tocaban bastante y yo me escondía siempre debajo de la mesa por el susto que me daba el que se disfrazaba del diablo; llevaba a la casa las gallinas vivas para preparar el sancocho de gallina para los domingos y me ponía a matarlas poniéndoles una tabla encima del cuello y yo tenía que pisar y así le quebraba el cuello contra el piso; también tenía que desplumarlas y quitarles todo, y había que echar todas las partes de la gallina a la olla, hasta los huevos que suelen traer algunas gallinas en su interior. Él comía de todo, patas, cuello, cabeza; le encantaban los tamales, las empanadas, el arroz, pero jamás ni el pescado ni las ensaladas. Nos hacía comer la sopa de cuchuco y como yo la detestaba, cuando terminaba el primer plato le decía a mi abuelita: 'Doña Blanca, traiga otro que a la niña le encantó y se va a comer otro', ¡era terrible i No había quién no lo obedeciera, porque él decía también: 'una orden mía, es una 
orden', pero jamás, debo decir, me tocó ni con un pañuelo. En realidad, sí inspiraba todo el respeto del mundo, pero nada de miedo. Siempre se preocupó de que la mesa estuviera llena de comida para todos. Aunque, nunca todo es tan bonito, porque lamentablemente, tomaba todos los días. Su alcoholismo fue su demonio. Pero prefiero acordarme de lo honesto, correcto, amable y bonachón que fue".

Y así prosiguió la reunión familiar, todos hablando a la vez de sus padres, tíos, abuelos y de que nunca se preocuparon por saber ni de su antepasado español ni nada. Pienso que esta generación simplemente no quiso recordar, no miraron al pasado porque la mayoría eran o hijos o nietos de las dos guerras mundiales, y por ende, se dedicaron a construir el presente mirando al futuro, porque recordar seguramente era terrible y doloroso. Pero ahora me encuentro yo aquí, lejos de los temores de esa generación, y queriendo saber de mi genealogía. ¿Quién soy? ¿De dónde vengo en realidad? Mi realidad es distinta, yo quiero mirar e indagar hacia el pasado y darme cuenta de cómo éste afecta mi presente y futuro, porque creo que existe algo que me lleva a trascender. Siento el deber y la obligación de traspasar mis recuerdos a las nuevas generaciones familiares para poder formar identidad, ¿será que el registro histórico inconsciente y colectivo del que habló Carl Gustav es el que me ha llevado a querer indagar sobre mi genealogía?

En lo más profundo de mi ser, sé que estoy conectada con los que habitaron antes de que yo naciera y sé que, a su vez, ellos estaban conectados con "el Único". Sé que soy fruto de un tronco muy viejo. Creo que cada uno de nosotros lleva dentro de sí un bagaje familiar e histórico, porque todos tenemos recuerdos personales, recuerdos familiares y recuerdos colectivos de un grupo. Ese colectivo que nos dice, como está escrito en el libro de Éxodo: "contarás a tus hijos y a los hijos de tus hijos...generación tras generación”, porque si no, ¿cómo explicar lo que me enseñó mi abuelo? Cuando era niña, él solía contarme muchas historias y cuentos, tal es así que aún recuerdo que hasta los amiguitos de la cuadra venían a sentarse y les gustaba escuchar sus historias; algunas de ellas perdurarían en mi memoria. Pasó el tiempo y fui creciendo. Al llegar a ser adulta joven, me convertí al cristianismo protestante, y así comencé a estudiar la Biblia y a conocerla, pero me llevé una sorpresa, iyo conocía muchas cosas que allí estaban escritas! Pero, ¿cómo las conocía? ¡Por mi abuelo!, sí, él me había enseñado gran parte del antiguo testamento ¡en forma de cuentos! Y según contaban las primas de mi mamá, al bisabuelo también le gustaba 
contar cuentos, historias, ¿de dónde había adquirido mi abuelo esta costumbre? ¿Dónde lo vio? Deduzco que en su casa, mi abuelito debió haber aprendido esto de su padre. Lo de traspasar la tradición oral es muy propio de los judíos y aún más, traspasar su conocimiento bíblico, porque muchos pueblos traspasan tradiciones, es cierto, pero sólo uno traspasa conocimientos del Antiguo Testamento.

El recuerdo se asimila y se transmite por una vivencia en el presente; mi abuelito tuvo que haber vivido algo simbólico que lo hizo traspasar lo que vivió, pero, ¿por qué me contaba a mí? ¿Porque soy la única de sus nietos en tener estos recuerdos? ¿Por qué nunca le contó estas historias a sus hijas? Me he preguntado si soy como el pariente escogido a quien se le revelan los secretos, y eso me hace sentir especial. Me siento como la escena que se describe en el libro "La Gesta del Marrano" cuando el médico Francisco Maldonado da Silva, le transmite a su hijo, en su secreta y jubilosa complicidad, todos los conocimientos y tradiciones que tiene sobre su pueblo: "los judíos", y le dice que son judíos por dentro, para sobrevivir en el espíritu. Pero, me surge una gran inquietud, mi abuelo era de todos los hijos el único católico, porque ningún otro hermano profesó la fe católica como tal, o, mejor dicho, ninguna fe. Aunque, ahora que lo pienso, los católicos tampoco tenían como costumbre traspasar el conocimiento del Antiguo Testamento. Son estas sutilezas las que, sin duda, abren, para mí, un mar de inquietudes y me harán seguir investigando profundamente al respecto.

Sin duda alguna para mi existe ese legado judío que traspasa las líneas del tiempo y existe a través de mi abuelo. Él me legó esta herencia que estaba en mi inconsciente, porque esto no es algo aislado sin historia, sin pasado, sin memoria sino que es algo que forma parte de muchos eventos que se desarrollan a través de miles de años y siguen sonando en mi memoria y en mi corazón. No sé si soy descendiente de judío, sigo investigando, pero en mi vida nunca han existido las coincidencias. No creo que haya una mera coincidencia entre la frase de mi abuelo “malditos judíos, judíos marranos” y el haberme enseñado gran parte de la Tora. A su vez, no hay coincidencia en haber ingresado al Centro de Estudios Judaicos de la Universidad de Chile. Para mí, existen una serie de sucesos muy entrelazados en mi vida que me han traído hasta aquí. Dios, el Señor tiene un propósito en mi vida. 


\section{FOTOS PRESENTACIÓN}

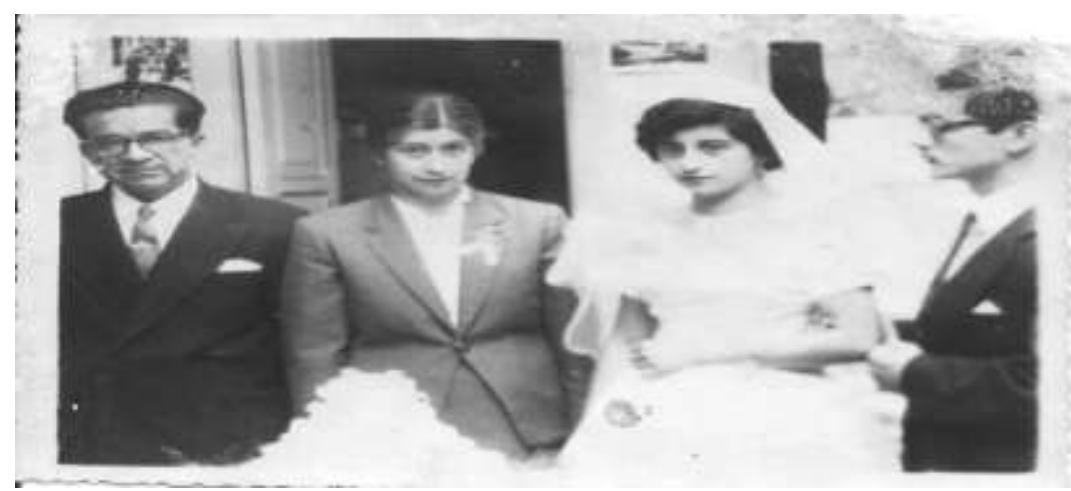

\section{FOTO 1}

Mis abuelos, Moisés Alegría y Blanca Sandoval el día de la boda de mis padres,

Leonor Esperanza y José Noel Hoyos .30 de Noviembre de 1957.

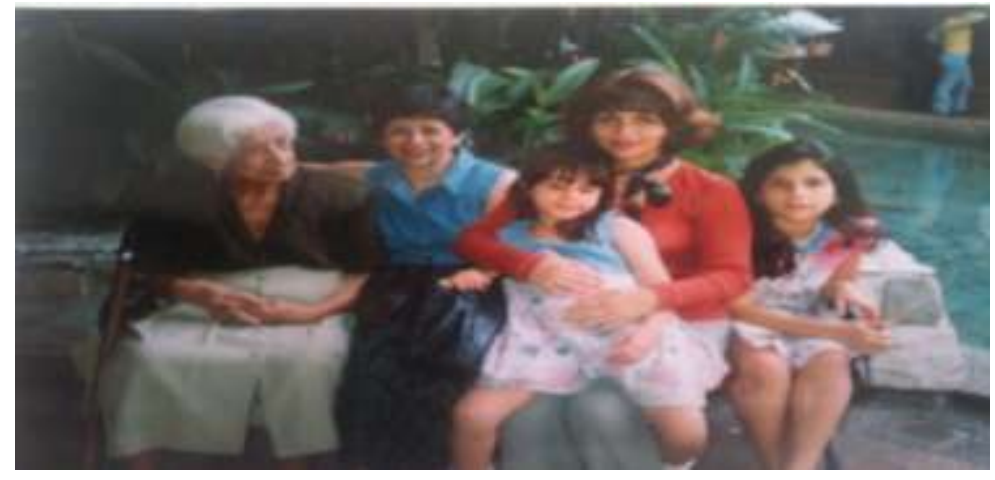

\section{FOTO 2}

Mi abuelita Blanca un día antes de mi partida a Chile. 29 de Junio 1.998 


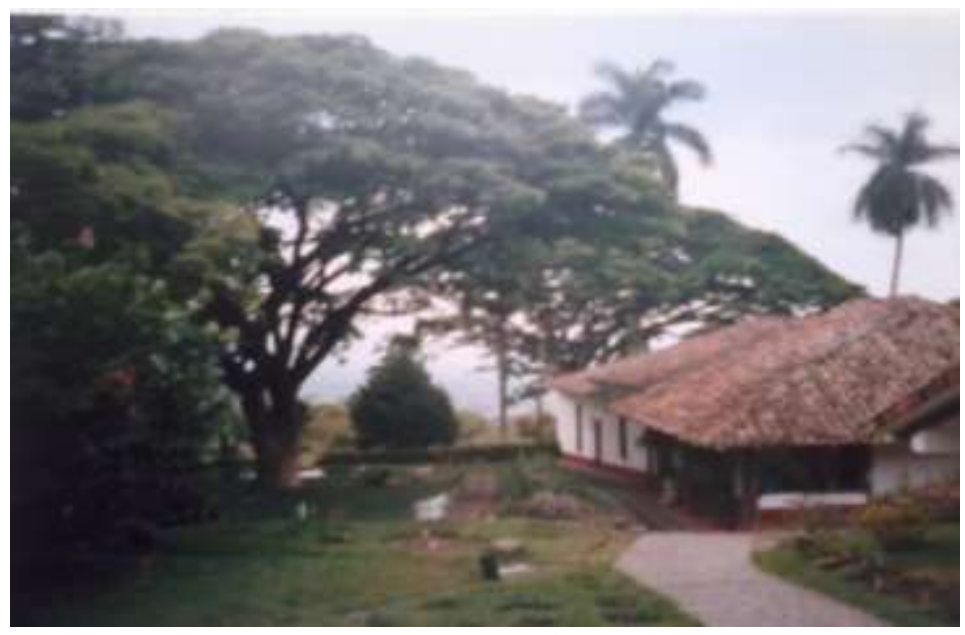

\section{FOTO 3}

Vista lateral de Hacienda "El Paraíso" Casa de Jorge Isaac autor de la novela latino americana "María"

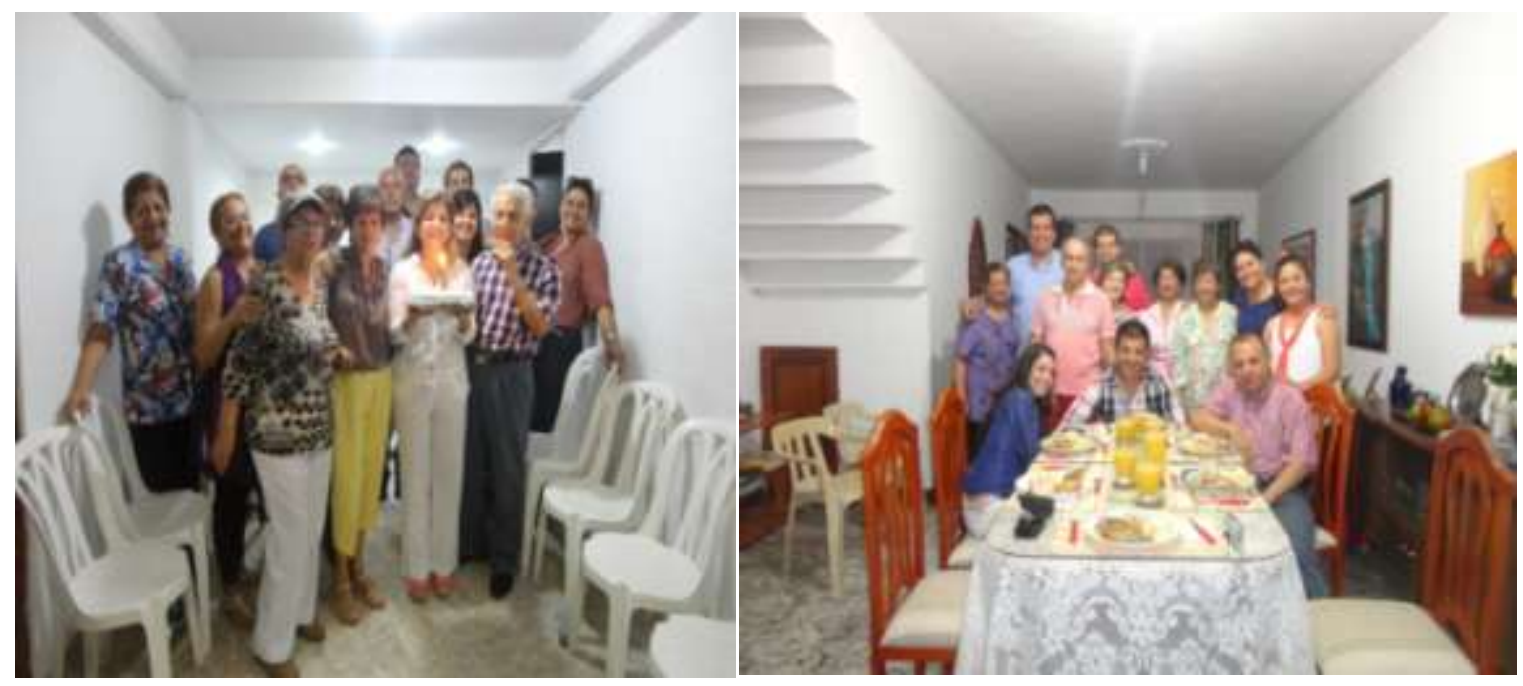

\section{FOTO 4 y 5}

Reunión familiar y celebración de cumpleaños. 


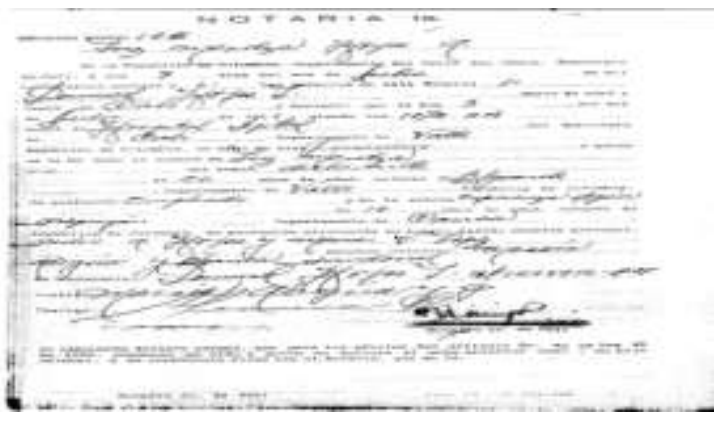

MI REGISTRO CIVIL DE NACIMIENTO 03-07-1961

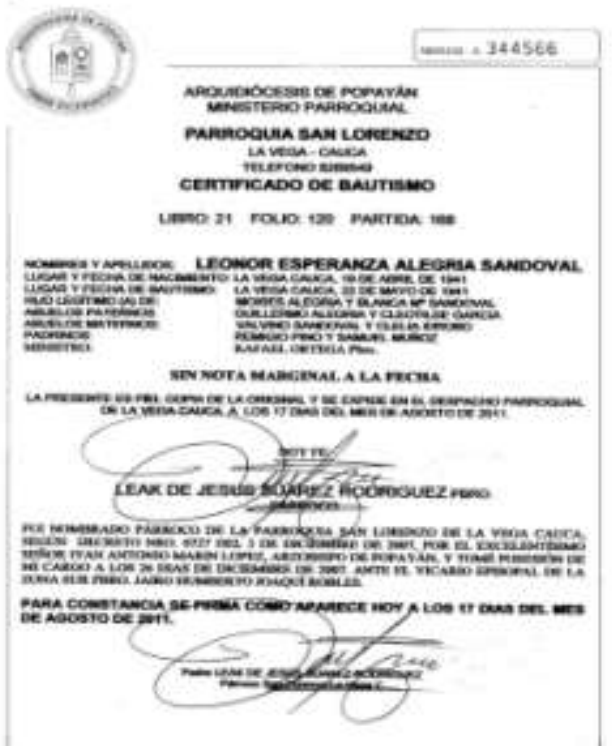

CERTIFICADO BAUTISMO DE MÍ MAMA ESPERANZA ALEGRÍA 19-04-1941

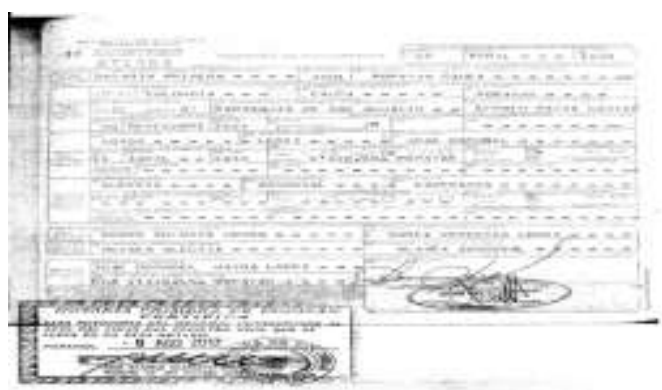

REGISTRO MATRIMONIO DE MIS PADRES 30-11-1957

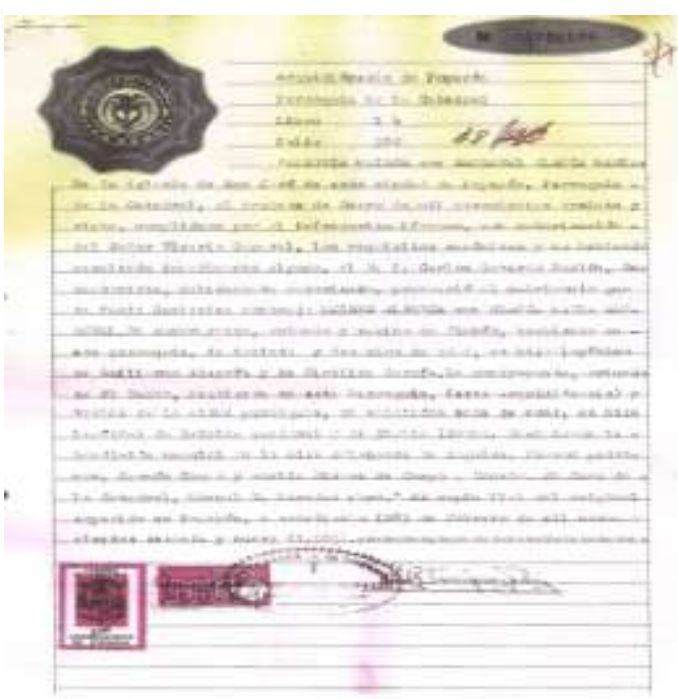
PARTIDA DE MATRIMONIO DE SUS PADRES MOISÉS ALEGRIA Y BLANCA SANDOVAL 30-01-1937




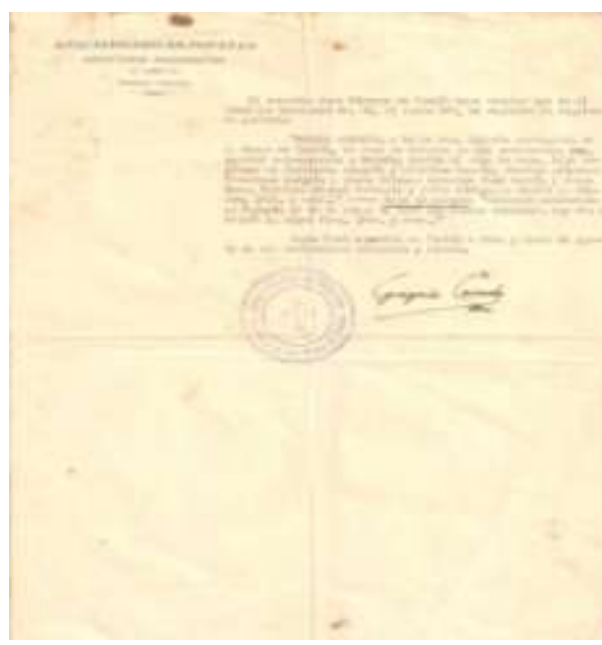

PARTIDA DE BAUTISMO DE MI ABUELO MOISÉS ALEGRÍA GARCIA

12-10-1902

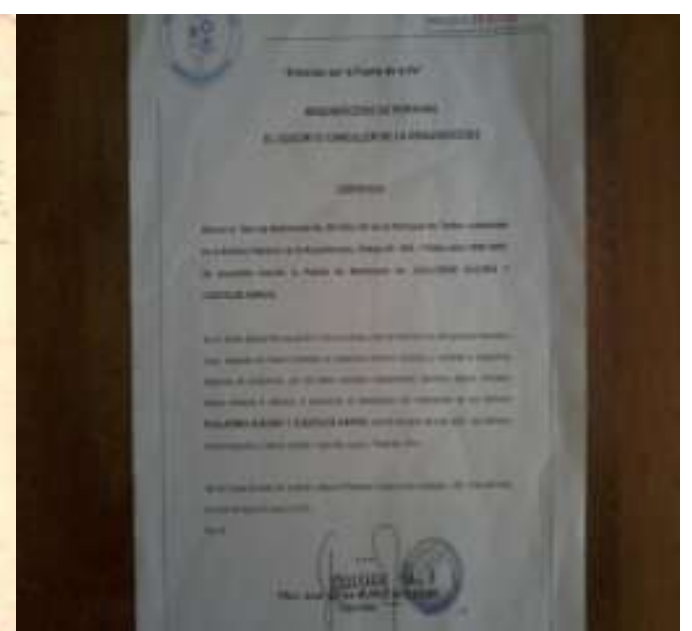

PARTIDA MATRIMONIO DE LOS PADRES DEL ABUELO MOISÉS. GUILLERMO Y CLEOTILDE 22-04-1895

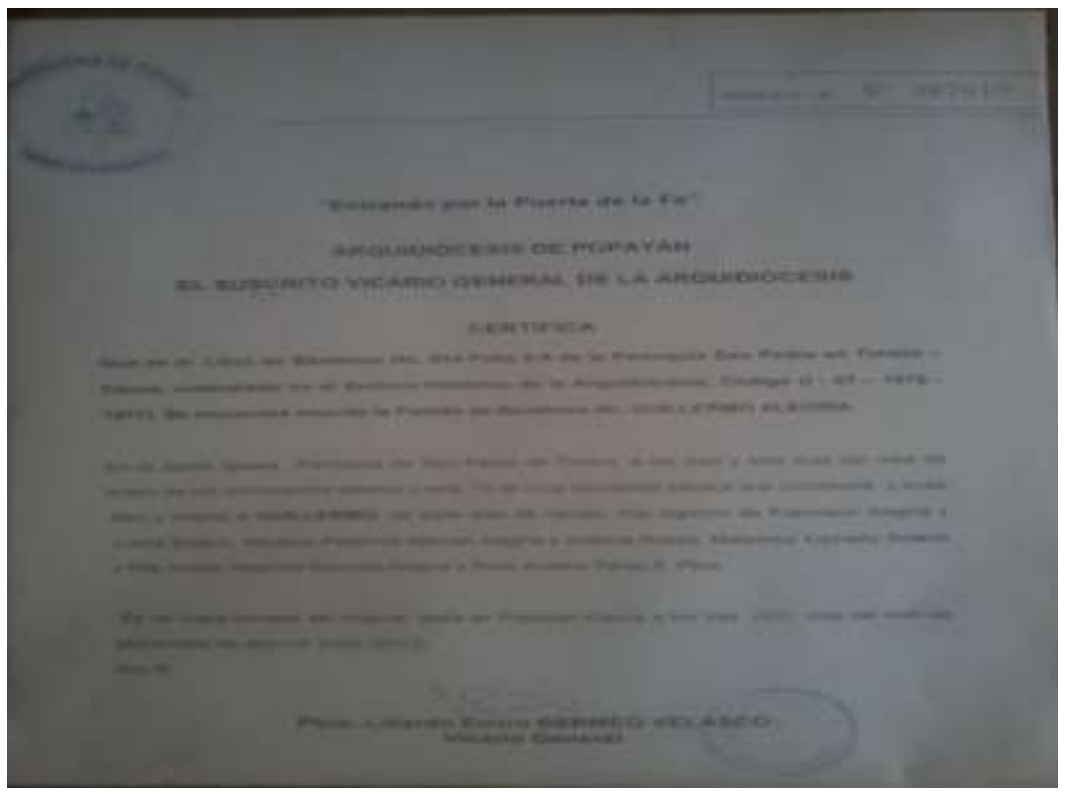

PARTIDA DE BAUTISMO DE MI BISABUELO GUILLERMO ALEGRÍA SOLANO $16-01-1876$ 


\section{ARBOL GENEALÓGICO FAMILIA ALEGRÍA}

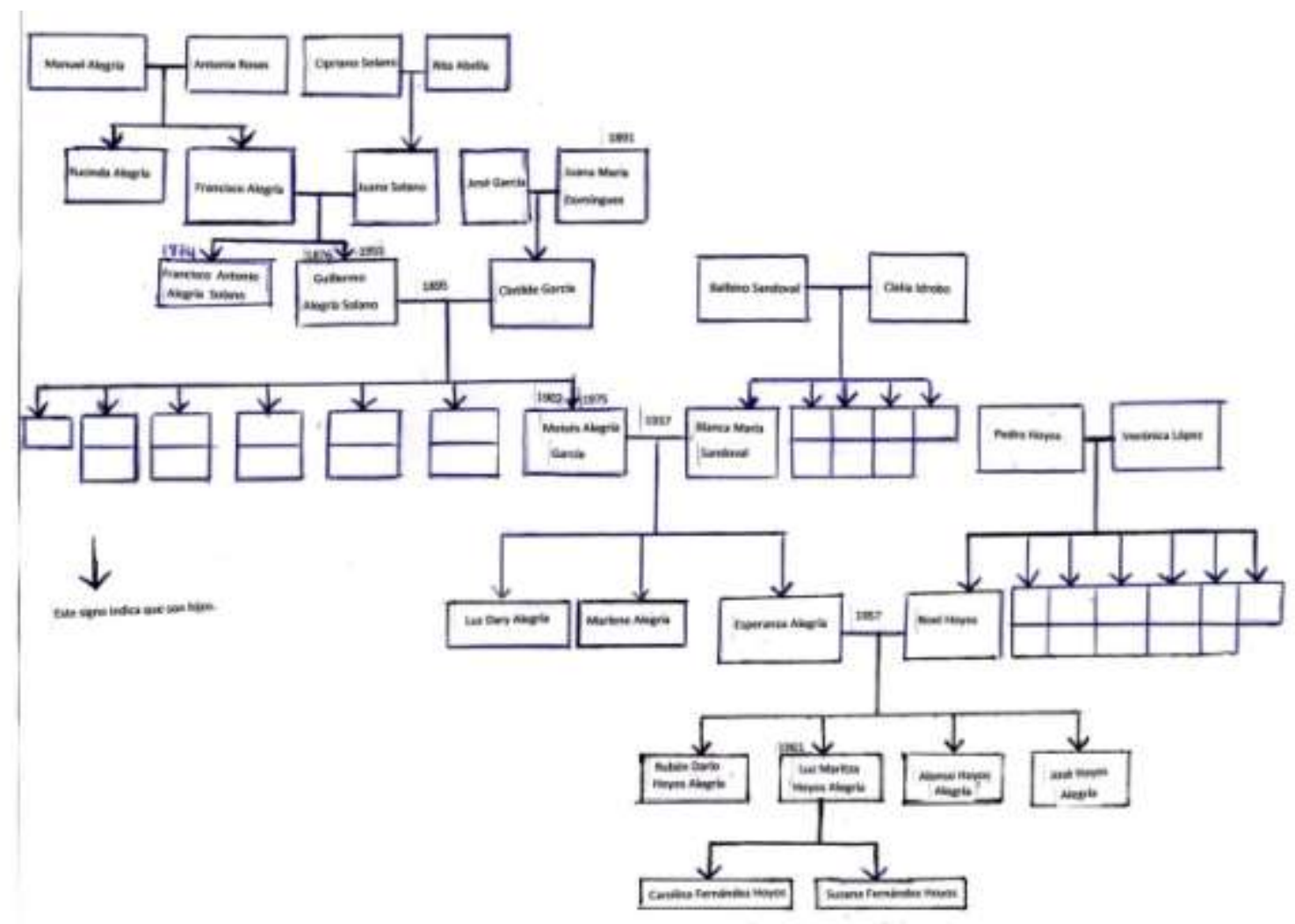




\section{Bibliografía}

Glantz, M. (2006). Las Genealogías. España: Pre-Textos

Isaacs, J. (2004). María. Bogotá: Ediciones Universales

Campos, J. "Margo Glantz. Judía, mexicana y rusa", Cuadernos Judaicos No 25, pp. 55-72, Centro de Estudios Judaicos, Facultad de Filosofía y Humanidades, Universidad de Chile, diciembre 2008.

Weinstein Levy, J. "Retrato de familia", Cuadernos judaicso No 29, pp.297-323, Centro de Estudios Judaicos, Facultad de Filosofía y Humanidades, Universidad de Chile, diciembre 2012.

Núñez Sánchez, J. (2010). "Inquisición y diáspora judía: Los Sefarditas de Chimbo". Ecuador. Cartilla de divulgación cultural, (42), 1-33.

Vila Vilar, E. (1979). "Extranjeros en Cartagena (1593-1630)" En: Jahrbuchfür Geschite Lateinamerikas, No 16, págs. 147-184. 